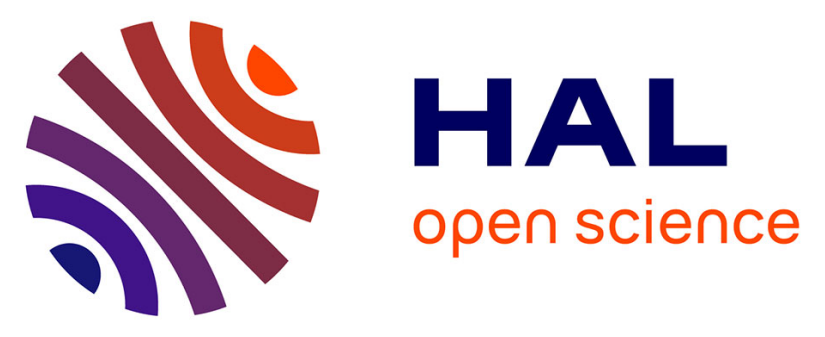

\title{
Hearing recovery after surgical resection of non-vestibular schwannoma cerebellopontine angle tumors
}

\author{
Naira Mkrtchyan, Lauranne Alciato, Michel Kalamarides, Daniele \\ Bernardeschi, Olivier Sterkers, Isabelle Bernat, Mustapha Smail, Nadya \\ Pyatigorskaya, Ghizlene Lahlou
}

\section{To cite this version:}

Naira Mkrtchyan, Lauranne Alciato, Michel Kalamarides, Daniele Bernardeschi, Olivier Sterkers, et al. Hearing recovery after surgical resection of non-vestibular schwannoma cerebellopontine angle tumors. European Archives of Oto-Rhino-Laryngology, 2021, 10.1007/s00405-021-06956-6 . hal03388097

\section{HAL Id: hal-03388097 \\ https: / hal.sorbonne-universite.fr/hal-03388097}

Submitted on 20 Oct 2021

HAL is a multi-disciplinary open access archive for the deposit and dissemination of scientific research documents, whether they are published or not. The documents may come from teaching and research institutions in France or abroad, or from public or private research centers.
L'archive ouverte pluridisciplinaire HAL, est destinée au dépôt et à la diffusion de documents scientifiques de niveau recherche, publiés ou non, émanant des établissements d'enseignement et de recherche français ou étrangers, des laboratoires publics ou privés. 
Hearing recovery after surgical resection of non-vestibular schwannoma cerebellopontine angle tumors

Naira Mkrtchyan, Lauranne Alciato, Michel Kalamarides, Daniele Bernardeschi, Olivier Sterkers, Isabelle Bernat, Mustapha Smail, Nadya Pyatigorskaya, Ghizlene Lahlou 


\section{$8 \quad \underline{\text { Abstract }}$}

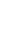

Purpose: Post-operative outcomes for hearing after resection surgery to remove cerebellopontine angle (CPA) tumors other than vestibular schwannomas (VS) are not well understood. This study presents a series of patients with significant postoperative hearing recovery, trying to define the incidence among all patients operated on for removal of non-VS CPA tumors. Methods: This is a retrospective observational case series of 8 patients among 69 operated on for removal of non-VS CPA tumors between 2012 and 2020. All patients had pre- and post-operative hearing measurement with pure-tone average (PTA) and speech discrimination score (SDS), according to the American Academy of Otolaryngology-Head and Neck Surgery recommendations, auditory brainstem response (ABR) measurements and imaging.

Results: Six meningiomas and two lower cranial nerve schwannomas operated on with a retrosigmoid approach were included for analysis. The mean pre-operative PTA and SDS were $58 \pm 20.7 \mathrm{~dB}$ and $13 \pm 17.5 \%$, respectively. All patients had pre-operative class D hearing and asynchronous ABRs. They all showed significant hearing recovery, with an improvement of $36 \pm 22.2 \mathrm{~dB}(\mathrm{p}=0.0025)$ and $85 \pm 16.9 \%(\mathrm{p}=0.0001)$ in PTA and SDS, respectively, with mean follow-up of $21 \pm 23.5$ months. Seven patients recovered to a class A hearing level and one patient to class B. The ABRs became synchronous for three patients. The incidence of auditory recovery was $13 \%$ for patients operated on with a conservative approach ( $\mathrm{n}=60)$.

Conclusion: A significant post-operative improvement in hearing could be a reasonable expectation in non-VS tumors extending into the CPA and a retrosigmoid approach should always be considered regardless of pre-operative hearing status. 6 (1)

(1)

9

\section{(1)} 1 2 
Introduction

The most common cerebellopontine angle (CPA) tumor is vestibular schwannoma (VS) which represents approximately $6 \%$ of all intracranial [1] and 91\% of CPA tumors [2]. Meningiomas are the second most common tumors of the CPA affecting $6 \%$ to $15 \%$ of patients [2]. Lower cranial nerve and trigeminal schwannomas are rare lesions and represent $0.7 \%$ and $1 \%$ of CPA tumors, respectively [3].

Regardless of the tumor histology, hearing loss is one of the most common symptoms of CPA tumors [4-7]. To date, when there is an indication for surgical treatment of these tumors, the choice of surgical approach is guided by the tumor size, growth, location and hearing level $[7,8]$. Although preservation of facial nerve function is still the main goal of surgery, hearing preservation should be considered whenever possible $[5,6,8,9]$.

Apart from VS, where hearing preservation was obtained in $43 \%$ of patients in a large series [10] and significant hearing recovery is not an expectable result, hearing recovery could be a reasonable expectation in non-VS CPA tumors since the they arise outside the acoustic-facial bundle. Up to now, only a few case reports have been published on hearing recovery after surgical resection of non-VS CPA tumors [4, 7, 11-15].

In this study, we evaluated the hearing results in non-VS CPA tumors with particular regard to those patients who had significant hearing recovery, trying to analyze the incidence of such events and the possible surgical implications.

\section{Materials and methods}

This article follows the STROBE (STrengthening the Reporting of OBservational studies in Epidemiology) [16] guidelines for the reporting of observational studies.

\section{Study population}

This monocentric retrospective study, conducted in a tertiary referral center, included patients who experienced significant hearing recovery after non-VS CPA tumor removal through a retrosigmoid approach between 2012 and 2020. All patients gave their informed consent for the use of their clinical data. The study complied with Public Health code (CNIL \#2211758). The inclusion criterion was a post-operative hearing improvement of more than $30 \mathrm{~dB}$ in pure-tone audiometry (PTA) and/or a $50 \%$ gain in the speech discrimination score (SDS).

Exclusion criteria were neurofibromatosis type II (NF2) related tumors, meningiomatosis, pseudotumors of the CPA (arachnoid and epidermoid cysts), tumors of the central nervous system extending to the CPA (pilocytic astrocytoma, choroid plexus papilloma, ependymoma, ganglioglioma) and revision surgical procedures. 
Pre-operative assessment

Before surgery, all patients underwent a clinical examination (facial nerve function was evaluated according to the HouseBrackmann (HB) grading system [17]), hearing assessment and neuroradiological examinations (high-resolution computed tomography and magnetic resonance imaging $[\mathrm{MRI}])$.

\section{Audiometric tests}

All patients were evaluated before surgery and post-operatively (at 1 month and at the last visit) by the same audiologist using similar testing equipment and procedures (pure-tone and monosyllabic speech audiometry). Audiometric data included PTA, calculated as the mean of the thresholds at frequencies of $0.5,1,2$ and $3 \mathrm{kHz}$ and SDS, calculated using a standardized presentation up to $40 \mathrm{~dB}$ sensation level or maximum comfortable loudness (whichever was lower). The differences between pre- and post-operative PTA and SDS were calculated (respectively $\triangle \mathrm{PTA}$ and $\Delta \mathrm{SDS}$ ). Hearing function was graded according to the American Academy of Otolaryngology - Head and Neck Surgery (AAO-HNS) guidelines: Class A: PTA $\leq 30$ $\mathrm{dB}$ and SDS $\geq 70 \%$; Class B: PTA $>30 \mathrm{~dB}$ and $\leq 50 \mathrm{~dB}$ and SDS $\geq 50 \%$; Class C: PTA $>50 \mathrm{~dB}$ and SDS $\geq 50 \%$; Class D: PTA any level and SDS $<50 \%$ ) [18]. Hearing recovery was defined as described above corresponding to a change in the AAOHNS hearing class from non-useful (Class D) to useful or normal hearing (Class A and B).

Pre-operative and post-operative auditory brainstem responses (ABR) using click were collected. Five waves (I-V) were recorded in the first $10 \mathrm{~ms}$ after broad-band and high-intensity stimuli. Three $90 \mathrm{~dB}$ acquisitions were made, followed by a decrease by $10 \mathrm{~dB}$ ranging up to the hearing threshold. ABR were classified as: Synchronous: reproducible ABR waves in three $90 \mathrm{~dB}$ stimulations and good visualization of wave $\mathrm{V}$ which decreased in intensity and increased in latency with decreasing stimulus intensity; Augmented inter-peak latency: good visualization of the ABR waves, but with a I-V inter-peak interval in the homolateral ear increasing by more than $0.5 \mathrm{~ms}$ compared to the contralateral ear; or Asynchronous: no visualization of a reproducible wave V, even at high-intensity stimulation. A detailed analysis of ABR curves has been carried out.

\section{Tumor imaging}

Pre-operative MRI allowed morphological characterization of the tumors for diagnostic orientation, measurement of their sizes and analysis of the acoustic-facial bundle position. The MRI protocol included at least a high-resolution 3D T2-weighted image (wi) to analyze the position of the acoustic-facial bundle and a 3D T1-wi after gadolinium chelate injection, allowing tumor characterization and measurements of tumor size in three axial directions (anterior-posterior, medio-lateral and superior-inferior). Brainstem displacement with or without mass effect in the fourth ventricle was collected. Meningiomas 
were classified according to the modified Desgeorges and Sterkers classification: Posterior petrous (P); Meatus and auditory canal invasion (M); Anterior petrous (A); Anterior petrous and meatus (AM); Posterior petrous and meatus (MP), and anterior and posterior petrous but also meatus (AMP) [19].

Surgery

We used two classifications usually used for VS. The quality of resection was classified following the Monfared classification as gross-total resection (no tumor remnant was visible at the end of surgery), near-total resection (the tumor remnant measured less than $5 \times 5 \times 2 \mathrm{~mm}$ over the brainstem and the facial nerve) or sub-total resection (the tumor was resected $80 \%$ to $90 \%$ by volume and $60 \%$ to $70 \%$ by surface area) [20]. The Jackler classification was used to describe the acoustic-facial bundle position with regard to the tumor: Facial nerve course pattern I: anterior-inferior shift of the VII-VIII bundle; Facial nerve course pattern II: anterior shift of the VII-VIII bundle; Facial nerve course pattern III: superior shift of the VII-VIII bundle; Facial nerve course pattern IV: posterior shift of the VII-VIII bundle [21, 22].

The anatomopathological results were listed, and the meningiomas were graded from I to III according to the World Health Organization (WHO) classification (2007 or 2016).

\section{Post-operative assessment}

Complications of surgery were assessed. Post-operative facial (HB) and lower cranial nerve functions were evaluated at the last follow-up. Audiometric tests and ABRs were performed at the last visit.

\section{Statistical analysis}

Results are presented as mean \pm SD for continuous variables and as numbers and percentages for categorical variables. Statistical analysis was performed using Prism (GraphPad Software, San Diego, CA, USA). The pre-operative and postoperative audiological results were compared using two-way ANOVA and Mann-Whitney tests. Differences between groups were considered to be significant for $p \leq 0.05$.

\section{Results}

Patients

Among 99 patients operated on between December 2012 and January 2020 for non-VS CPA tumors, 69 were eligible for this study, from whom 60 were operated on with a retrosigmoid approach (Fig. 1). A significant post-operative hearing recovery 
was found in eight patients who were included in this study, representing $13.3 \%(8 / 60)$ of all non-VS CPA tumors operated on with a conservative approach. Patient characteristics for inclusion are detailed in the flow chart (Fig. 1).

\section{Baseline characteristics}

Baseline characteristics of the 8 patients with hearing recovery are described in Table 1 . Their mean age was $58 \pm 9.9$ years [40-72 years]. The right side was involved in half of the cases. One patient had pre-operative grade II HB facial nerve function. All patients had a significant degree of pre-operative hearing loss. For all patients but one, who had a sudden hearing loss which was unresolved after 5 days of corticosteroid therapy, the hearing loss was progressive, with an average evolution of 1 year. Patients were not premedicated with steroids or other drugs in the pre-operative period.

Tinnitus and balance disorder were present in one and four cases, respectively. Two patients were experiencing hemifacial hypoesthesia. Regarding lower cranial nerve function, one patient, affected by a lower cranial nerve schwannoma, had a X and XI palsy. One of the patients had morning headaches suggesting early intracranial hypertension.

\section{Pre-operative assessment}

Hearing

Complete audiological data were available for all eight patients (Table 1). The mean pre-operative PTA was $58 \pm 20.7 \mathrm{~dB}$ and SDS was $13 \pm 17.5 \%$. All patients presented with class D hearing. ABR were asynchronous for all patients, but in 3 patients, we identified the isolated presence of wave I at $90 \mathrm{~dB}$ stimulation.

Imaging

In all cases, the pre-operative MRI allowed a correct diagnosis of tumor histology. The mean tumoral measurements in the three axial directions were $32 \pm 5.8 \mathrm{~mm}, 28 \pm 6.9 \mathrm{~mm}$, and $31 \pm 5.0 \mathrm{~mm}$ for anterior-posterior, medio-lateral and superior-inferior diameters, respectively.

Six patients had a significant brainstem compression (Fig. 2), four with and two without fourth ventricle displacement/compression. No hydrocephalus was observed pre-operatively. Four patients showed internal auditory canal invasion.

Regarding the displacement of the acoustic-facial bundle, in two cases, an anterior course was observed, while it was anteriorsuperior in two cases, superior in two others and no nerve deviation and posterior-inferior switch in the two remaining patients. 
Surgery

All patients were operated on with a retrosigmoid approach using a continuous facial nerve monitoring system (NIM ${ }^{\circledR}$, Medtronic, Minneapolis, MN, USA).

Intraoperative displacement of the acoustic-facial bundle by the tumor was as follows: two patients had facial nerve course pattern I, one had pattern II, and five had pattern III. Gross total resection was achieved in four cases, and sub-total resection in four (Table 1). MRI analysis of the VII-VIII bundle displacement matched the intraoperative observed displacement in five cases.

Regarding the histological analysis, the most common lesion was CPA meningioma ( $\mathrm{n}=6$ ), followed by lower cranial nerve schwannoma $(n=2)$ (Table 1). Four of the six meningiomas were classified as grade I in the WHO classification, and the other two as grade II. The proportion of grade I and grade II in our series was comparable to the proportion in the entire cohort (52 grade I WHO and 8 grade II WHO).

\section{Post-operative assessment}

Hearing

The mean follow-up was $21 \pm 23.5$ months [1-54 months]. At the last visit, $\Delta$ PTA was $36 \pm 22.2 \mathrm{~dB}$, with a significant improvement at all frequencies ( $p<0.0001$, two-way ANOVA, $\mathrm{n}=8$, Fig. 3A), and $\Delta$ SDS was $85 \pm 16.9 \%(p=0.0002$, MannWhitney test, n=8, Fig. 3B). There was no significant difference between the hearing results at 1 month and at the last visit, or the mean PTA $(20 \pm 9.7 \mathrm{~dB}$ vs $18 \pm 10.6 \mathrm{~dB}, \mathrm{p}=0.25$, Mann-Whitney test), or the mean SDS $(95 \pm 8.8 \%$ vs $92 \pm 18.9 \%$, $p>0.999$, Mann-Whitney test). Table 1 shows the results for all patients at the last visit.

After surgery, all patients but one recovered from a pre-operative hearing class D to a post-operative class A; the last patient recovered to class $\mathrm{B}$.

Concerning ABRs, three of the five available post-operative ABRs became synchronous, one became synchronous with increased interpeak interval I-V, and only one remained asynchronous.

\section{Complications}

Regarding early post-operative complications, one patient experienced a post-operative cerebrospinal fluid leak (7 days after surgery) which required revision surgery.

One patient had a well-tolerated post-operative paralysis of the X and XI nerves (Patient 5) and another had reversible grade II facial paralysis that required no further treatment (Patient 1). The patient presenting pre-operative grade II HB facial nerve 
function recovered to grade I (Patient 8). Lower cranial nerve functions were improved in Patient 7, with disappearance of the $\mathrm{XI}^{\text {th }}$ nerve paralysis, improved laryngeal sensitivity, but persistence of ipsilateral vocal cord palsy.

\section{Imaging}

Post-operative imaging was available for seven patients. Three had a residual tumor, located in the jugular foramen in two and in the cavernous sinus in one patient (Table 1). All but one residual tumor were stable; the last one showed growth that was treated with Gamma-knife stereotactic radiosurgery.

\section{$\underline{\text { Discussion }}$}

Analyzing our results, among the 69 patients operated on for a non-VS CPA tumor at our institute, we were surprised to note that the incidence of significant hearing recovery was $13.3 \%$ after tumor removal with a retrosigmoid approach. These patients experienced a recovery from non-useful hearing (class D) to useful hearing with intelligibility (class A or B), that probably represents a substantial improvement in their everyday quality of life. During the same period, in nine cases, we used a translabyrinthine approach for non-VS CPA tumor removal (Fig. 1), because of significant pre-operative hearing loss. It is likely that some of them would have experienced hearing recovery if we had used a retrosigmoid approach in those cases. Therefore, at present, the retrosigmoid approach is the preferred option when dealing with non-VS CPA tumors despite the hearing level and/or the tumor volume, and this has represented an important change in our daily practice.

In the literature, there are a few reports $[4,7,11-15]$ on hearing recovery after CPA tumor removal (Table 3 ), most being case reports generally concerning meningiomas, arachnoid and epidermoid cysts. We decided not to include the cysts in our series because they were not "true" tumors with different biological and histopathological behaviors. Only one study reported a large series of CPA meningiomas [4] and found some degree of hearing improvement in 40 of 421 cases. Unfortunately, they used the Hannover Audiological Classification making comparison with the present study difficult.

Although preservation of hearing in surgical treatment of VS has been emphasized and discussed in the literature [10], little is known about auditory function in non-VS tumors of the CPA. However, extrapolating data on hearing preservation in VS surgery to the post-operative evolution of hearing for non-VS CPA tumors is probably a mistake. First, in VS, pathophysiological evidence indicates that hearing loss is explained by compression of either the cochlear nerve and/or the labyrinthine artery in the internal auditory canal (IAC) with a direct association between VS tumor size and hearing loss [23]. In the case of labyrinthine artery compression, vascular damage to the cochlea with no conceivable recovery could explain the hearing loss. The significant recovery of hearing obtained in this series suggests that the vascular etiology was not involved, similar to a report by Lanzino et al. [7] who described hearing recovery after marsupialization of a CPA arachnoid 
cyst in a patient who had recordable pre-operative otoacoustic emissions (OAEs) with an asynchronous ABR. The presence of OAEs pre-operatively may predict the integrity of vascular supply to the cochlea and correlation studies would be necessary to define their function in pre-operative care [24]. Similarly, the presence of wave I in the pre-operative ABR, which indicates the cochlear synapse function, could have the same significance and be a good prognostic factor for hearing recovery [25]. Indeed, we found the presence of wave I pre-operatively even in the case of asynchronous ABR, and it could be helpful to use OAEs as an additional tool to select cases with a greater chance of hearing recovery.

In addition, histological evidence of invasion of the cochlear nerve by VS was reported by Neely et al. [26]. In contrast, in non-VS CPA tumors, although the pathophysiology evidence is poor, hearing loss is probably due to cochlear nerve compression without invasion [14], which would not cause irreversible damage to the nerve and the cochlea, making hearing improvement possible. Indeed, we know that damage to the cochlear nerve cannot be repaired, but compression by a tumor may cause neurapraxia that, once the pressure is alleviated, allows return of axonal transmission and hearing recovery. Thus, the decompression of the cochlear nerve by the tumor removal could allow spectacular recovery of the SDS, as illustrated in our series.

Regarding other post-operative functional outcomes, a good post-operative facial nerve function was obtained in all patients, despite the presence of relatively large lesions, underlining the fact that, when dealing with large CPA lesions, the facial nerve is not at increased risk during a retrosigmoid approach compared to a translabyrinthine approach. Finally, the choice of the extent of resection in our series was mainly decided after considering lower cranial nerve function. In two cases, the lesion arose from these nerves and a gross-total resection might have led to lower cranial nerve injury.

Surgery is not the sole option for treating these lesions. Gamma-knife stereotactic radiosurgery has been employed in the treatment of meningiomas [27] and lower cranial nerve tumors [28]. Results on hearing preservation have been published [27] and a mention of hearing improvement has been reported in that series without any audiological data. Because of the volume of tumors in our cases, radiosurgery was not indicated as first-line treatment. In addition, chemotherapy with bevacizumab could be associated with an improvement in hearing in NF2-related VS, but this treatment is reserved for patients with NF2 and no indications are accepted for other kinds of CPA tumor. The mechanism of hearing recovery is thought to be a decrease in intraneural edema and vascular shrinkage of the tumor which would decrease the compression on the nerve and blood vessels [29].

There are some important limitations that could affect the generalizability of our findings. First, the retrospective nature of this study encompasses biases that are difficult to overcome. Also, we did not use intraoperative auditory monitoring in this study. Looking at our cases, pre-operative ABR were asynchronous in almost all patients making this kind of monitoring impossible. Monitoring with cochlear nerve action potentials (CNAP) would have provided interesting information about the 
variation of this potential during manipulation of the tumors with the possibility of individualizing some surgical steps/maneuvers important for hearing recovery [30]. Finally, we tried to highlight anatomic, audiological or radiological factors to compare the different groups presented in the flow chart (Fig. 1), but the heterogeneity of their presentation and the relatively small number of patients did not allow us to constitute a statistically significant control group.

\section{Conclusion}

We would like to alert readers to the potential for significant post-operative hearing recovery in non-VS CPA tumors and stress the importance of considering a conservative surgical approach, even in cases of severely impaired hearing and large tumors. Relying on tumor size and hearing status for choosing the translabyrinthine approach (as classically performed for VS) should not be adopted in non-VS CPA tumors. Larger multi-center studies examining this topic would help corroborate our results. 


\section{References}

1. Lin D, Hegarty JL, Fischbein NJ, Jackler RK (2005) The prevalence of "incidental” acoustic neuroma. Arch Otolaryngol Head Neck Surg 131(3):241. https://jamanetwork.com/journals/jamaotolaryngology/fullarticle/648807. Accessed 7 Jan 2020

2. Brackmann DE, Bartels LJ (1980) Rare tumors of the cerebellopontine angle. Otolaryngol Head Neck Surg 88:555559. https://doi.org/10.1177/019459988008800508

3. Moffat DA, Saunders JE, McElveen JT, et al (1993) Unusual cerebello-pontine angle tumours. J Laryngol Otol 107:1087-1098. https://doi.org/10.1017/s0022215100125393

4. Nakamura M, Roser F, Dormiani M, et al (2005) Facial and cochlear nerve function after surgery of cerebellopontine angle meningiomas. Neurosurgery 57:77-90; discussion 77-90. https://doi.org/10.1227/01.neu.0000154699.29796.34

5. Miller ME, Mastrodimos B, Cueva RA (2012) Hearing preservation in management of epidermoids of the cerebellopontine angle: CPA epidermoids and hearing preservation. Otol Neurotol 33:1599-1603. https://doi.org/10.1097/MAO.0b013e31826bed8d

6. Batra PS, Dutra JC, Wiet RJ (2002) Auditory and facial nerve function following surgery for cerebellopontine angle meningiomas. Arch Otolaryngol Head Neck Surg 128:369-374. https://doi.org/10.1001/archotol.128.4.369

7. Lanzino G, diPierro CG, Ruth RA, et al (1997) Recovery of useful hearing after posterior fossa surgery: the role of otoacoustic emissions: case report. Neurosurgery 41:469-472; discussion 472-473. https://doi.org/10.1097/00006123-199708000-00029

8. Tator CH, Nedzelski JM (1985) Preservation of hearing in patients undergoing excision of acoustic neuromas and other cerebellopontine angle tumors. J Neurosurg 63:168-174. https://doi.org/10.3171/jns.1985.63.2.0168

9. Cohen NL, Lewis WS, Ransohoff J (1993) Hearing preservation in cerebellopontine angle tumor surgery: the NYU experience 1974-1991. Am J Otol 14:423-433. https://doi.org/10.1097/00129492-199309000-00002 
10. Daoudi H, Lahlou G, Degos V, et al (2020) Improving facial nerve outcome and hearing preservation by different degrees of vestibular schwannoma resection guided by intraoperative facial nerve electromyography. Acta Neurochir (Wien) 162:1983-1993. https://doi.org/10.1007/s00701-020-04397-4

11. Goebel JA, Vollmer DG (1993) Hearing improvement after conservative approach for large posterior fossa meningioma. Otolaryngol Head Neck Surg 109:1025-1029. https://doi.org/10.1177/019459989310900609

12. Maurer PK, Okawara SH (1988) Restoration of hearing after removal of cerebellopontine angle meningioma: diagnostic and therapeutic implications. Neurosurgery 22:573-575. https://doi.org/10.1227/00006123-19880300000023

13. Vellutini EA, Cruz OL, Velasco OP, et al (1991) Reversible hearing loss from cerebellopontine angle tumors. Neurosurgery 28:310-312; discussion 312-313. https://doi.org/10.1097/00006123-199102000-00024

14. Christiansen CB, Greisen O (1975) Reversible hearing loss in tumours of the cerebello-pontine angle. J Laryngol Otol 89:1161-1164. https://doi.org/10.1017/s0022215100081536

15. Lewis ML, Echols DH (1951) Pearly tumor of the cerebellopontine angle, report of a case with reversible deafness. Laryngoscope 61:1123-1125. https://doi.org/10.1288/00005537-195111000-00006

16. von Elm E, Altman DG, Egger M, et al (2007) The Strengthening the Reporting of Observational Studies in Epidemiology (STROBE) Statement: Guidelines for reporting observational studies. PLoS Med 4(10):e296. https://doi.org/10.1371/journal.pmed.0040296

17. House JW, Brackmann DE (1985) Facial nerve grading system. Otolaryngol Head Neck Surg 93:146-147. https://doi.org/10.1177/019459988509300202

18. (1995) Committee on Hearing and Equilibrium Guidelines for the Evaluation of Hearing Preservation in Acoustic Neuroma (Vestibular Schwannoma): Committee on Hearing and Equilibrium. Otolaryngol Head Neck Surg 113:179-180. https://doi.org/10.1016/S0194-5998(95)70101-X

19. Peyre M, Bozorg-Grayeli A, Rey A, et al (2012) Posterior petrous bone meningiomas: surgical experience in 53 patients and literature review. Neurosurg Rev 35:53-66; discussion 66. https://doi.org/10.1007/s10143-011-0333-6 
20. Monfared A, Corrales CE, Theodosopoulos PV, et al (2016) Facial Nerve outcome and tumor control rate as a function of degree of resection in treatment of large acoustic neuromas: Preliminary Report of the Acoustic Neuroma Subtotal Resection Study (ANSRS). Neurosurgery 79:194-203. https://doi.org/10.1227/NEU.0000000000001162

21. (2020) Atlas of Skull Base Surgery and Neurotology. https://www.thieme.com/booksmain/neurosurgery/product/787-atlas-of-skull-base-surgery-and-neurotology. Accessed 8 Jan 2020

22. Esquia-Medina GN, Grayeli AB, Ferrary E, et al (2009) Do facial nerve displacement pattern and tumor adhesion influence the facial nerve outcome in vestibular schwannoma surgery? Otol Neurotol 30:392-397. https://doi.org/10.1097/MAO.0b013e3181967874

23. Remenschneider AK, Gaudin R, Kozin ED, et al (2017) Is the cause of sensorineural hearing loss in patients with facial schwannomas multifactorial? Laryngoscope 127:1676-1682. https://doi.org/10.1002/lary.26327

24. Mom T (2007) [Otoacoustic emissions in clinical and surgical practice]. Ann Otolaryngol Chir Cervicofac 124:8089. https://doi.org/10.1016/j.aorl.2006.09.002

25. Huo Z, Chen J, Wang Z, et al (2019) Prognostic factors of long-term hearing preservation in small and medium-sized vestibular schwannomas after microsurgery. Otol Neurotol 40:957-964. https://doi.org/10.1097/MAO.0000000000002284

26. Neely JG, Hough J (1986) Histologic findings in two very small intracanalicular solitary schwannomas of the eighth nerve. Ann Otol Rhinol Laryngol 95:460-465. https://doi.org/10.1177/000348948609500505

27. Jahanbakhshi A, Azar M, Kazemi F, et al (2019) Gamma Knife stereotactic radiosurgery for cerebellopontine angle meningioma. Clin Neurol Neurosurg 187:105557. https://doi.org/10.1016/j.clineuro.2019.105557

28. Ruangkanchanasetr R, Lee JYK, Nagda SN, et al (2018) Toxicity of Gamma Knife radiosurgery may be greater in patients with lower cranial nerve schwannomas. J Neurol Surg B Skull Base 79:580-585. https://doi.org/10.1055/s0038-1651504

29. Plotkin SR, Stemmer-Rachamimov AO, Barker FG, et al (2009) Hearing improvement after bevacizumab in patients with neurofibromatosis type 2. N Engl J Med 361:358-367. https://doi.org/10.1056/NEJMoa0902579 
30. Simon MV (2011) Neurophysiologic intraoperative monitoring of the vestibulocochlear nerve. J Clin Neurophysiol 28:566-581. https://doi.org/10.1097/WNP.0b013e31823da494 
Fig. 1 Flow chart of the study population

$\Delta$ PTA: difference between pre- and post-operative pure tone average; $\Delta$ SDS: difference between pre- and post-operative speech discrimination score.

Fig. 2 Axial and coronal views of MRI scans (cerebellopontine angle meningioma) from Patient 1 Pre-operative Fast imaging employing steady-state acquisition in axial (A, upper left) and coronal (B, lower left) images showing a stage IV tumor with brainstem compression; and post-operative axial (C, upper right) and coronal (D, lower right) images showing a total tumor resection with acoustic-facial bundle visualization.

Fig. 3 Evolution of hearing between the pre-operative period and the final post-operative visit

A: Pre- and post-operative mean of thresholds of the tonal audiogram at 500,1000, 2000, and $3000 \mathrm{~Hz}$, showing a significant improvement of thresholds $(\mathrm{p}=0.0152, \mathrm{p}=0.0054, \mathrm{p}=0.0002$ and $\mathrm{p}=0.0017$, respectively; two-way ANOVA with SIDAK's multiple comparison test).

B: Significant improvement of the pre- and post-operative speech discrimination score ( $\mathrm{p}=0.0002$, Mann-Whitney test). 